\title{
Effective Cultural and Economic Indicators on Business Communications Growth (With an Emphasis on Iran)
}

\author{
Saeideh Babajani Mohammadi ${ }^{1}$, Hossein Takroosta ${ }^{2} \&$ Mohammad Amin Takroosta $^{3}$ \\ ${ }^{1}$ Faculty of Management Department in Ferdows Higher Education institutions of Mashhad, Iran, Mashhad \\ ${ }^{2} \mathrm{Ph}$. D. student in Management, Ferdowsi University of Mashhad (FUM), Iran, Mashhad \\ ${ }^{3}$ MS. C. student in Economic, Allame Tabatabaee University (ATU), Iran, Tehran \\ Correspondence: Saeideh Babajani Mohammadi, Faculty of Management Department in Ferdows Higher \\ Education institutions of Mashhad, Iran, Mashhad. Tel: 9809-1501-5780. E-mail: babajani.saeideh@gmail.com
}

Received: January 31, 2016

doi:10.5539/mas.v10n11p67
Accepted: February 25, 2016

Online Published: July 29, 2016

URL: http://dx.doi.org/10.5539/mas.v10n11p67

\begin{abstract}
Today, society became an international trade lifeline. The study of this science has become a necessity to understand the cultural differences in intercultural communication. Although it increasingly crossed the borders and business barriers had been denied, but cultural boundaries do not sidestep easily and unlike legal, political, or economic, business environment tangible aspects, culture is largely invisible. Hence, an aspect of international trade is often overlooked. For economic growth and development inside and outside the borders, attentions should be paid to the cultural aspects of our society and other societies.

The purpose of this study was to evaluate the effect of cultural dimensions on growth of economic indicators. This study is a practical in terms nature and purpose, and is descriptive, and library study in terms of data collection. In order to data collection, questionnaire and financial information of financial institutions were used (information of economic indicators of Asian Development Bank and the Central Bank of the Islamic Republic of Iran). Validity and reliability of the questionnaire were evaluated through Cronbach's alpha and exploratory and confirmatory factor analyses were done. The population in this study was the country's capital market participants. Sampling was done through probabilistic sampling strategy and simple random sampling method was used and 92 persons were estimated through the Morgan table. Structural equation modeling was used, to test the hypotheses. The results of this study showed that, there is a positive relationship between cultural dimensions and growth of economic indicators.
\end{abstract}

Keywords: cultural dimensions, communication, globalization, economic indicators

\section{Introduction}

Globalization is a fact that the world is facing, whether it is a historical and spontaneous inevitability or planned and imposed project. Given that the markets are going towards globalization; so deregulation and competitiveness of the market would makes organizations to adapt to new goals and make plans to change the strategy (Jaros, 2010).

Despite the importance of this issue, we are witness of organizations failure reports in this area. One of the reasons for the high failure rate is failure to understand cultural differences and the presence of culture of changes avoidance in organizations. Culture is rooted in the values (Hwang, 2005) and its signifycance for the 21 st century is such an extent that some people consider it as "century of culture and cultural paradigm" and some people remember the emergence of the sixth continent as "culture continent" (Ebrahimian, 2012; Mostafavi, 2013). According to the expression of the importance of culture and globalization of trade; the most desirable method is their interactive effects on each other. Therefore, in the study of theoretical concepts, globalization, culture and communication are studied.

Today, the world is witnessing massive and amazing transformation of economy, communications, culture, politics, international treaties and affairs in the globalization. The globalization process due to its broad scope is affected all facets of human life; for this reason, some scholars have considered it as the greatest event in human history. Therefore, globalization and its discussion can't be ignored. Indeed, globalization has created a communication revolution, and the world has become a village. 
In the past, human relations and communications were limited to geographic areas, but today with the movement towards the global village and eruption of the communication revolution, human trade exchanges are not confined to a geographic area anymore. Businesses have grown and spread throughout the world. Hence, appropriate and effective communication for the survival and success of businesses would be necessary. Despite the globalization of businesses environment, merchants of each area are committed to their regional customs and culture. To achieve a successful business at the international level, merchants should manage their communications by acquiring information about the culture of their business; respect the opponent's principles and the impacts of cultural dimensions of economic indicators in the country, because this communication awareness will lead to loss of cultural misunderstanding. In this paper, we decided to review the factors affecting the growth of economic indicators which is the groundwork for establishing a successful business by evaluating cultural aspects of selected GLOBE studied Asian countries.

\section{Theoretical Foundations}

Given the importance of the interactions of globalization, communication and culture, in this section, the literature of each section are reviewed.

\subsection{Globalization}

Term of globalization has been used in scientific and literary texts since the 1960s. According to Giddens, globalization means deepening of social relations in large level, so that the distances become insensible and the cause of an accident at a location can be searched in a quite different and far area (Safiri \& Nematollahi, 2012; Khanifar, Zarvandi \& Zarvandi, 2010). Robertson stated that globalization is not merely a process of visual communication, but also it refers to mental knowledge and hope (Rangkesh, 2010). Lucas (2004) expressed that globalization is a continuous flow of internationalization's historical path which increases dependence of countries to each other in economic, political, cultural, and especially environmental aspects. Globalization has caused that your problem, be our problem (Zahedi, 2011; Beigi, 2011).

Globalization means liberalization, elimination of trade barriers, means deterritorialization (Mikami, 2011), or development of integration the areas into a single realm (Ghaheri, 2010; Tavakol \& Zadmehr, 2011), or creation a glass border (Millar Wood, 2008).

Some scholars have used metaphors to define globalization and they believe that, globalization is a historical process (Dlanty, 2000); project or scheme (Latvsh, 2000; Darvishi, 1378; Ham, 1999; Friedman, 1995); a phenomenon (Nash, 2001; Nasri, 2001; Dadz, 2000); development of human's common values (Ham, 1999); a new meta-discourse (Tajik, 2001); a domain oriented expansion (Held, 1999) (Quoting et al., 2004). Definitions of globalization focuses on three common elements; creating an integrated economy in global level (same market); creating transnational governments and third prism is increasing information and communication resulting from technology development (Millar, 2008).

In the phenomenon of globalization three factors; proximity, location and attitude are related to each other. Proximity; at the current time than any other time in the past, countries are close to each other and they must observe more regulations. Location; location of companies and their integration activities are beyond the international borders and creating permanent competition. Attitude; in the globalization phenomenon, the countries with a new perspective pay attention to performances at the global level. In this attitude, the world outside the country's border should be considered from one side and they need to grow their abilities on the other hand, so that they can take an active role in the international system (Stoner, Freeman \& Gilbert, 2005). Globalization has created a revolution in communication, and the world has become a village (Wong, 2007) and for success in global environmental communication skills, including knowledge of the cultural dimension should be reinforced.

\subsubsection{Dimensions of Globalization}

Globalization is studied in two dimensions, internal (according to performance indicators in the field of human, financial, structural and efficiency resources) and external (due to the globalization of the economy, technology, politics, culture). With the globalization literature review, most researchers have pointed to the exterior dimensions of globalization (Turner, 2004; Ameli, 2004; Miller Wood, 2008; Movius, 2010; Liu, 2010). Economic dimension: Globalization, for the first time was extensively highlighted by researchers in the field of economy, but nowadays everyone admits that, this concept has spread to other areas of human life (Tajik \& Darvish, 2004). Political dimension: The political impact of globalization is considered on the sovereignty issue. Of course, complete separation of the political dimensions of economic and cultural aspects of society is not possible. Cultural dimension: In this dimension, there are deep concerns about the threat of invasion and the 
decline of norms, values, and indigenous and local beliefs (Pour Ezzat, Gholipour, Bagheri \& Naddaf, 2011).

\subsection{Culture}

Increasing the attention to issues of intercultural communication arose after publication the book of the cultural achievements of Hofstede (1980), which was the most influential works in this area. Hofstede's work presented a five cultural dimensions value system and plotted a cultural map of the world with 53 countries. In the GLOBE study (2004), the cultural map of the world was plotted with investigating 9 cultural dimensions among 62 countries and in the last GLOBE study (2007), was plotted with investigating 25 countries.

\subsubsection{Dimensions of Culture}

In this section, three famous studies of Hofstede's four cultural dimensions and KluckHohn's six dimensions and GLOBE's nine dimensions study were investigated. The research results of Hofstede, lead to the expression 4 dimensions (differences) of culture. These dimensions are:

- $\quad$ Power distance; the extent to which, people with less power in a society accept unequal power and consider it as a common event (Mansouri, Motiei, Shekarriz \& Nejati, 2013). In a country like Denmark, low power distance means that the acceptance of inequality for people is difficult.

- Uncertainty; ways in which human societies have learned to cope with uncertainty. The technology often is used to defend against the natural uncertainty. Religion is a cultural tool, which helps us to accept the uncertainties that we can't defend against them. The cultures characterized by low avoidance of uncertainty, accept the individuals with innovative ideas, abnormal and deviant behavior. While, there is resistance to the phenomenon in cultures characterized by high avoidance of uncertainty (Oughi, 2011). Acceptance degree of ambiguity should not be mistaken with risk avoidance, this doesn't include the willingness of people to take risks, but also it is associated with preferences for clear rules and principles (Mansouri Sepehr et al., 2013; Oughi, 2011).

- Individualism versus collectivism; in individualistic cultures, individuals do activities independently from the other members of the society. In many countries, this case is considered as a very undesirable case. In individualistic societies, the connections between individuals are weak and everyone is expected to take care of themselves and their immediate families. In these communities, personal interests precede the interests of the group (Oughi, 2011). In collectivist cultures, cohesive groups, give people a sense of identity and belonging and due to its sense of security, it demands considerable loyalty.

- Masculinity versus female-oriented: in cultures with high masculinity, the men are expected to play a positive and assertive and with specific business goals along with career progression path and increase revenue. Women are responsible for supervisory roles and interpersonal relationships and appropriate environment (ibid).

These cultural traits can be thought as a part of the semantic context that shapes the culture (Johich, 2002). A Canadian man named Michael Bond added the fifth dimension entitled long-term orientation to four dimensions of Hofstede (Aarabi \& Omid, 2009). This dimension represents the degree to which a society has pragmatic and based on future approach instead of having a cross-sectional and short-term view (Mansouri et al., 2013).

KluckHohn and Strodtbeck framework is the most common framework to distinguish cultures from each other. The criteria with six dimensions:

- Man and nature; is human subdues of natural and environmental factors and compromise with them? Or governs it? In basic terms, goal setting can’t be taken seriously, but in the second situation people are looking for their own purposes.

- Culture and time; is the culture pay more attention to the present and future or the past? If it pays much attention to the present and future, so time is gold for this culture. But if it pays attention to the past, time doesn't have value and programs are often short-term. This dimension enables individuals to engage in any society to realize its long borders.

- Culture and space or location ownership; some cultures are very open and very clear, but some cultures prefer the privacy and confidentiality issues (Robbins, 1998).

Definitions of Cultural Dimensions of the Globe Study

The most comprehensive research in the field of culture is the studies of House et al. (2004) and Kokar et al. (2007) known as the GLOBE study. Iran has been investigated in both studies. This research was done in collaboration with more than 150 social scientists (as cultural representatives of different parts of the world) by 
distributing 17,000 questionnaires 825 organizations, food industry, telecoms and banks. In This study, national cultures are classified based on 9 dimensions.

1) Performance oriented: The extent to which an organization or society rewards its members for performance improvement and excellence. This dimension of Mc Kland's study is about success. In cultures where there is a high need to succeed, there are people who launch new businesses and organize productive and economic units and increase productive capacities (House et al., 2004; Kokar et al., 2007).

2) Future oriented: Represents the extent to which people in society or organization involve in the future behaviors such as planning and future investment and don't associate with the present's success. The important point is that, the performance doesn't improve in the long term, unless the culture contains values and norms that can help organizations to adapt to changing environment. However, the long term thinking should be dominant in programs (ibid).

3) Assertiveness: Represents the degree to in which people in society or organization are decisive, aggressive and aggressive in social relations. In such cultures, organizational strategy has an entrepreneurial orientation. In organizations with high certainty, people are encouraged to competition and ambition. The level of participation and involvement in employees is high. The dominant approach is based on the organization's ability to do works and to make the emphasized results, the desire to victory is distributed among all members of the organization and it is believed that success depends on effort (ibid).

4) Power distance: An agreement between the members of an organization or society about dividing power unequally. In cultures with high power distance, organizational structures tend to be high and decisions tend to be concentrated, but in low power distance, decision-making are participative (ibid).

5) Human oriented: Represents the extent to which an organization or society rewards people for being fair, gallantry, friendly, generous, caring and kindness toward others. This dimension retrieved from Maslow's humanistic psychology that emphasizes is on the identification and development of human potential and it combines with measures such as creating confidence, promising, optimism, peace of mind and emotional intelligence. This situation provides groundwork for the creation of an appropriate and friendly institutional environment (ibid).

6) Institutional collectivism: Represents the extent in which an organization or society encourages collective actions and teamwork. This dimension measures societal emphasize on collectivism so that it leads individuals and groups to integration. The opposite of social collectivism is individualistic. Individualism represents the tendency to violate norms and intensifying motivation for seeking success. Both of these tendencies can lead to entrepreneurship (ibid).

7) In- group collectivism: This dimension is different from the institutional collectivism. It refers to people's loyalty toward family members or local organizations in which they serve and the extent to which people are proud to join in these collections concerned about its integration. In fact, individual's commitment to the organization causes the acceptance of the overall organization's goals and values, tendency to strive for organize, intention to continue their membership in the organization. Finally, optimum use of individual differences and enhances motivation led to the formation underlying innovative behaviors (ibid).

8) Uncertainty avoidance: The extent to which a culture encourages or rejects risk-taking culture. In cultures with low uncertainty, people tend to experience less stress from ambiguous situations and are more prepared to take risks. High uncertainty accurately and clearly identifies duties and on the other hand, it is a threat; because, people are resistant to change and innovation (ibid).

9) Gender egalitarianism: Reflects the extent in which the organization or society minimizes the differences in gender roles and sexism. In other words, the opportunity to achieve higher positions in organizations and society for men and women are equal. This equal possibility for upgrade increases the level of trust in the organization. This causes the tendency of women to participate more and take advantage of their competence (ibid, Faani, Babashahi, Afkhami Ardakani \& Ebrahimi, 2012).

In this paper, the four cultural dimensions; boldness, individualism and collectivism, power distance, uncertainty avoidance and its impact on economic indicators, intercultural communication and trade success were discussed.

\subsubsection{Typology of culture}

The metaphor is sometimes used to introduce the culture, some of which include: Network, society members as nodes, nodes that have bonded through their shared concerns (Mcveli, Duberley \& Johnson, 2007). Shredder; they are social, inconsistent, ambiguous, multi- species cultures and they are placed in continuous and fluid 
mode. Social glue; culture is viewed as glue that holds the sections of the society together (ibid). Culture is a control tool; researchers believe that, most of the basic regularities in social life arising from cultural systems (Scott, 2003; Mcveli et al, 2007). Power; culture is power and impacts on political, ideological, economic and military fields (Tomilson, 1999; Ameli, 2004). Culture is a living civilization (Ameli, 2007). Culture is a rooted and critical variable that is used by two means. Independent external variables that have impacts on the society (culture of the society) and internal independent variables that are the values and styles of one or more sub-culture (Scott, 2003).

In each society, there is often a dominant culture and a set of different subcultures. Dominant culture; emphasizes on the basic values shared by the members of the society and subcultures; reflects the issues, situations and experiences that members have encountered. If the dominant culture is strong, people respect fundamental social values. Because most of them are adopted and stick to it. Subcultures may don't have agreement, but they will support the values within the culture with a high intensity (Johich, 2002).

It can be said organizations' culture in every society is influenced by the prevailing culture. Organizational culture affects all organizational aspects and based on common values and beliefs of the organization empower the individual behavior, attitude, motivation, job satisfaction and affection. Just with review, modify, and create a good organizational and flexible culture, the interaction pattern between people can be changed in the organization and knowledge management can be utilized as a competitive advantage (Sadeghi et al., 2010).

\subsection{Communications}

In organizational communication theory, metaphors assist the theory: Pizza, the organization is a pizza in which people (flour), communications (the water that keeps the flour warm) and goals (yeast) is (Miller, 2011). Machine; emphasizing that each part of the machine performs a specific job, so each connection should be established. Each machine has a predictable result. Conduit, tool or channel; communications are technology transmission and communication tools to achieve organizational goals. Lens; organizations are such as a perceptual phenomenon or eyes that control the environment and filter and sort the data. Link; communications can be led to contact patterns and interdependence between individuals. Symbol; comes from the culture and knows communications as a literal interpretation such as stories, rituals and traditions (intergenerational communications) (Dadmehr, 2010).

\subsubsection{Challenges of Organizational Communication}

Challenges facing the organizational communication are because of the complexity of today's world. In this section, some aspects are discusses.

1) Globalization: What should be done for this challenge? The answer is in the application of communication accommodation theory and understanding the cultural differences (Tourish \& Hargie, 2004). Today, due to the increasing global communication and creating multinational corporations and cultural diversity, increasing knowledge and human skills to confront the conflicts and issues in a global society are the definitive requirements. In different cultures, and even subcultures within a national culture, there's a range of emotions. In the absence of understanding, development of good working relationships would be difficult. Understanding cultural differences or cultural intelligence is the factor that is taken into consideration in this context and it is the deflator.

Understanding of effective communication in terms of time and place in world markets is the cultural understanding in the workplace, international and multinational organizations (Miller, 2011) in exchange for the purposes of conflict management and colloquial language across cultures (Tourish et al., 2004), understanding how to protect the rights of native workers in the country, understanding how to organize political and economic policy (Miller, 2011), understanding and knowledge of organizational rules and norms of communication inside and outside the face to face communication to the mail and negotiate, necessary communication skills to achieve personal, team and organizational goals in organizations' framework, and self-openness to cultural awareness and differences (Tourish et al., 2004), so that it reduce intercultural communication barriers and gives people the cultural diversity management power (Abzari \& Khani, 2010).

The concept of cultural intelligence for the first time was raised by Earley and Ang (2004). The ability to learn new patterns is defined in cultural interactions and provides appropriate behavioral responses to these patterns. Ang et al. identified four factors in the cultural intelligence hypothesis to measure. They are:

- Motivational cultural intelligence: The personal tendency to experience other cultures and communicate with people in other cultures. 
- Meta cognitive cultural intelligence: This means that, how a person understand the intercultural experiences and describes the processes that people apply for business and understanding cultural knowledge.

- Cognitive cultural intelligence: It is a knowledge that represents an understanding of cultural similarities and differences and shows the general knowledge and intellectual and cognitive maps of other cultures.

- Behavioral Cultural Intelligence: This shows the person's ability in consistent with the verbal and nonverbal behaviors that are appropriate for dealing with different cultures (Hamidi, Andam \& Feizi, 2013).

All of the above can be summarized in four axial skills in that the connection is effective communications: International business knowledge, cultural compatibility, the ability to understand the perspective of others, the ability to play a role in innovation.

2) Climate Changes: Climate change increases the communications development for production of energy systems, build factories and transportation. Communications development is an opportunity for business and increasing environmental responsibility (Miller, 2011).

3) Population changes: Age, breed, income, educational attainment and etc. Outsourcing occurs especially in the environments in which corporations are multinational. How can establish communications with workers from different cultures? (ibid) and establish a multi-cultural management. Management in these organizations creates the major conflicts for customers, suppliers, employees and managers (Eisenberg, 2009).

4) Communication and culture: Intercultural communication is a communication between people in those cultural perceptions and symbolic systems are distinct enough from each other that present the communication phenomenon differently. In intercultural communication commonalities and differences should be found. And events should be analyzed and interpreted. One of the major features intercultural communications is the inevitability of conflicts and misunderstanding. In intercultural encounters, there's a good chance that the behavior of others does not meet our expectations. When it happens, that behavior will naturally be interpreted as violation of our value system. Intercultural Communications can be considered as a third culture. The results of interaction between two cultures' representatives are different.

\subsection{Tips on Cultural Differences}

- Value systems may be different, but no culture is better or correcter than another.

- The difference is not generally negative; the aim is understanding that how people see the world and it is important how we communicate with these differences.

- $\quad$ People should not be judged solely on the basis of a cultural dimension.

- When we increase our awareness, we can expect that others will have their own views.

- In order to understand someone from another culture, we need to understand the $3 p$ of culture (Perspective, Practice, Product) (Abzari and Khani, 2010).

\subsection{Intercultural Communication and Negotiation}

Communications is the basis of all connections and commercial and social interactions. In intercultural communications many things can prevent the common understanding, because people with different cultures don't have common ground or similar codes and conventions. Negotiation is a particular communicative situation in which the parties' goals are in conflict potentially. Although all negotiations are in the same process, the emphasis on each stage of the process considerably varies between the cultures. Since the negotiations are controversial, knowing these notes that when, how and to what extent we should have adapted behaviors, require very high cultural intelligence.

\subsection{Problems of Intercultural Communication}

Today the communications have become an international trade lifeline and to understand the cultural differences in intercultural communications, the study of this science has become a necessity. Cultural differences in micro and macro levels, lead to disruption of communication and mutual understanding (Pazoki Zadeh \& Tishedar, 2010). Communications within each society have high complex interactions and when a relationship is created between the two societies with different cultures, these interactions become more complex. When messages are transferred across cultural boundaries, it will be encrypted in one context and it will be decoded in another context. In this type of communications there are misunderstandings and unexpected reactions.

Culture usually refers to those specific behavioral characteristics that are reflected through verbal and nonverbal communication (Robbins, 1996). Differences in cultural values and deduction, often leading to a lack of understanding among people who have different cultural and historical backgrounds and incorrect understanding 
of the concepts and practices in areas such as language, interaction, nonverbal communications, and values, in turn, lead to irreparable damage to the relationship between culture (Aarabi \& Hedayati, 2009). On the other hand, understanding cultural differences provides the way to make an effective communication in the workplace. Learning the skills to effectively communicate with different cultures in today's world is very important.

According to Edward Hall, the famous anthropologist, "Culture is communications and communication is culture". Many of the challenges are rooted in cultural differences and misunderstandings in communication (Pazoki Zadeh et al., 2010).

According to theoretical principles and what is mentioned in the related researches, hypothesis can be stated as follows:

Hypothesis 1: Societies that have high boldness significantly are more successful in their intercultural business communication.

Hypothesis 2: Societies that have high individualism significantly are more successful in their intercultural business communication.

Hypothesis 3: Societies that have low power distance significantly are more successful in their intercultural business communication.

Hypothesis 4: Societies that have low uncertainty avoidance significantly are more successful in their intercultural business communication.

Hypothesis 5: Societies that have high understanding of cultural differences significantly are more successful in their intercultural business communication.

Aarabi and Hedayati (2009) presented a strategic model for their research on Hofstede's four cultural dimensions in the Iranian governmental organizations. The results of the studied population showed high uncertainty avoidance, high power distance, high female orientation and high collectivism.

Table 1. Iranian cultural features (Faghihi, Vaezi \& Aaghaz, 2010)

\begin{tabular}{|c|c|}
\hline Cultural Features & Source \\
\hline $\begin{array}{l}\text { Individualism and attention to links and strong family } \\
\text { communications }\end{array}$ & $\begin{array}{l}\text { Gable,1959; Keddie, 2002; Javidan \& } \\
\text { Hadizadeh Dastmalchian, 2003; Bar, 2004; } \\
\text { moghadam \& Assar, 2008; Sadeghkhani, 2007; Hofstede, } 2005 \\
\text { Sari al-Ghalam, 2007; Iran Nezad, } 2006\end{array}$ \\
\hline $\begin{array}{l}\text { Authoritarianism and granting special privileges to the } \\
\text { holder of the power }\end{array}$ & $\begin{array}{l}\text { Gable, 1959; Javidan \& Dastmalchian, 2003; } \\
\text { Bar, 2004; Hofstede, 2005; Yeganeh \& Sue, } 2007 \\
\text { Homayoun \& Katouzian, } 2005\end{array}$ \\
\hline Rejection of dissenting views & $\begin{array}{l}\text { Javidan \& Dastmalchian,2003 } \\
\text { Sari al-Ghalam, } 2007\end{array}$ \\
\hline Uncertainty avoidance & $\begin{array}{l}\text { Javidan \& Dastmalchian, 2003; Hofstede, 2005; Gable, 1959; Bar, 2004; } \\
\text { Iran Nezad, } 2006\end{array}$ \\
\hline $\begin{array}{l}\text { Strong orientation toward getting success and superior } \\
\text { performance }\end{array}$ & Javidan \& Dastmalchian, 2003; Bar, 2004 \\
\hline Low level of foresight and a short-term trends & $\begin{array}{l}\text { Javidan \& Dastmalchian, 2003; Bar, 2004; Yeganeh \& Sue, 2007; } \\
\text { Homayoun \& Katouzian, } 2005\end{array}$ \\
\hline Care about for human dignity & $\begin{array}{l}\text { Gable, 1959; Javidan \& Dastmalchian, } 2003 \\
\text { Iran Nezad, } 2006\end{array}$ \\
\hline Low trust towards each other & $\begin{array}{l}\text { Gable, 1959; Keddie, 2002; Javidan \& } \\
\text { Dastmalchian, 2003; Bar,2004; Yeganeh \& Sue, } 2007 \\
\text { Sari al-Ghalam, } 2007\end{array}$ \\
\hline Valuing rationality and yet operating emotionally & Iran Nezad, 2006; Bar, 2004 \\
\hline $\begin{array}{l}\text { Valuing hard work and enthusiasm and yet escape from } \\
\text { liability }\end{array}$ & $\begin{array}{l}\text { Mohseni, 2000; Bar, 2004; the findings of the surveying in } 28 \text { provinces of Iran: } \\
\text { Iranian values and attitudes, } 2001\end{array}$ \\
\hline
\end{tabular}

Hofstede's study placed Iranian culture in the bureaucratic culture with tendency to participatory and tribal culture. In a survey by the Mehraban Far and Noubari (2013), unlike Hofstede, who selected an organization as his target population, managers of Industries and Mines, Islamic Guidance, municipal council members, centers 
of 30 provinces were selected as the target population with 745 persons. The purpose of this work was to compare the conditions in the two periods in 1980 and 2006, the following results were obtained:

- In power distance dimension: $64 \%$ orientation towards high power distance

- In uncertainty avoidance: $87 \%$ orientation towards very high uncertainty avoidance

- In collectivism: $82 \%$ orientation towards collectivism

- In masculinity: $67 \%$ orientation towards masculinity

The comparison between the results of research in a 27 -year interval:

- $\quad$ Score of power distance from 52 to 64

- $\quad$ Score of uncertainty avoidance from 53 to 87

- $\quad$ Score of individualism from 18 to 45

- Score of masculinity from 45 to 67 is reached.

Increasing the Iranian culture's orientation in the past 27 years to the high power distance, high uncertainty avoidance, high masculinity and high collectivism represents the consolidation of culture in passing the previous years.

The GLOBE study by House et al. 2004 and Kokar et al. 2007 is one of the most prestigious studies of cultural dimensions on the global level. In these two studies, Iran's rank in 9 dimensions is as following: Activism with a high-ranking number 4.58 (expressing the tendency to very high welfare), foresight with a very low number 3.70 (stating the lack of attention to planning for the future), gender equality with a lower rank number 2.99 (stating the dominance of men in different areas), boldness with a median number 4.04 (represents low boldness in activity), individualism and collectivism with a relatively moderate number 3.88 (represents high collectivism), power distance with a high-ranking number 5.43 (represents a very high power distance), humanism with a high-ranking number 4.23 (stating the obviousness of people's emotions to each other), uncertainty avoidance with a relatively high ranking number 3.67 (stating the lack of attention to innovation and willingness to past methods) are estimated.

Eimay (2007) evaluated the effects of cultural intelligence (Note 1) (understanding cultural differences) on the effectiveness of intercultural business negotiations among western Asian and American negotiators, in that cultural intelligence is introduced as a key factor in the effectiveness of intercultural negotiation. Exploratory analyzes of this study suggest that individuals with cultural intelligence, have a stronger predictive power than others. Because, cultural intelligence is the capacity that allows individuals to have a good understanding of a wide range of cultures and appropriately act (Thomas, 2006).

According to above contents and thinking about stated objectives in order to communicate successfully with other countries, cultural dimensions must be considered. Based on this conceptual model can be presented as follows.

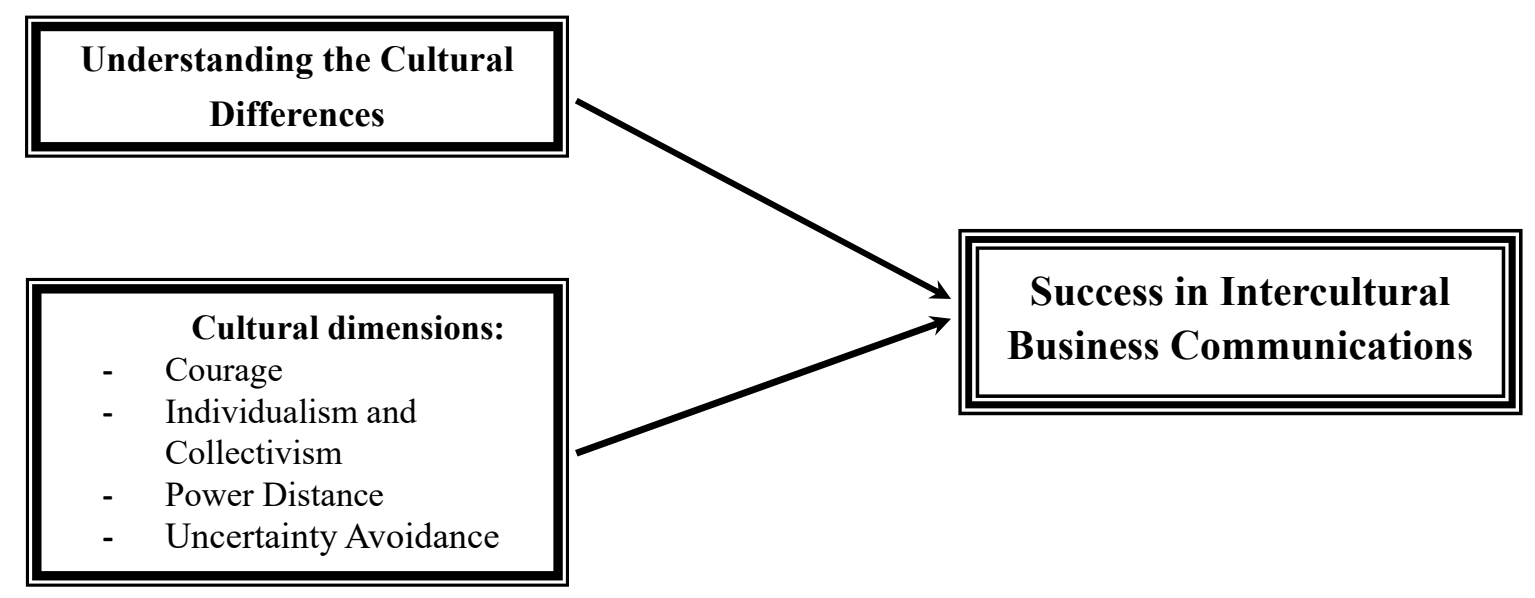

Figure 1. Conceptual model

\section{Research Methodology}

This study is a practical in terms nature and purpose, and is descriptive, and library study in terms of data collection. 92 questionnaires were distributed between economic activists (including commercial managers of 
350 companies listed in Tehran Stock Exchange and members of the Chamber of Industry and Mines) and analyzes were performed on these questionnaires. In this study, researchers operated five variables for the hypothesis test. GLOBE study standardized questionnaire (2004) was used to assess the cultural dimensions and Cultural Intelligence Questionnaire of Ang et al. (2004) was used to assess the understanding of cultural differences. This questionnaire has been used in several studies in Iran. Reliability and validity of this questionnaire have been approved by Kazemi (2008), Vedadi et al. (2009) and Taslimi et al. (2009) (Eghdampour, Mehrdad \& Jafari, 2011).

Fifteen economic indicators for the fifteen countries in this study include; Gross domestic product, added value in agriculture, added value in mining and industry, added value in services, percentage of non-governmental consumption costs, percentage of governmental consumption costs, percentage of gross capital formation, percentage of the exports value, percentage of the imports value, percent growth of the liquidity increase, percent growth of the liquidity increase to GDB, percentage of interest rate on investment in one year (short-term), the growth of consumer total index (inflation), the growth of foodstuffs index, the growth of manufacture index. This data for Iran was used from the database of the Central Bank of Iran and for other Asian countries was used from published information by the Asian Development Bank. In Table (2), number of designed items to measure cultural dimensions for Iran, Cronbach's alpha and reliability of aspects were presented. It is noteworthy that cultural aspects information of other countries exist in GLOBE book (2004), which has been used.

Table 2. Cronbach's alpha coefficient and reliability of the cultural dimensions

\begin{tabular}{lll}
\hline Dimensions & Number of items & Cronbach's alpha \\
\hline Boldness & 8 & 0.803 \\
Uncertainty avoidance & 8 & 0.822 \\
Power distance & 12 & 0.722 \\
Individualism and collectivism & 12 & 0.746 \\
Understanding the cultural differences & 19 & 0.840 \\
\hline
\end{tabular}

Note. As can be seen, Cronbach's alpha coefficients of all dimensions in this study is more the minimum value of 0.6 (Nunnally, 1978), 0.65 (Lee \& Kim, 1999).

\subsection{Assessment of Structural Validity}

To assess the structural validity, confirmatory factor analysis is used (Houman, 2008, p 17). The validity of the cultural dimensions was assessed using LISREL software. This software is measured using correlation and covariance and it can estimate or infer factor loading values, the variances and latent variables errors and it can be used for confirmatory factor analysis and etc. In the confirmatory factor analysis, experimental data are described, explained and justified based on a relatively small number of parameters. This model is based on experimental information about the structure of the data. The study has five cultural dimensions. All these aspects are latent variables and their measurement is determined using a structural model. Figures one to four show the confirmatory factor analysis using LISREL software. 

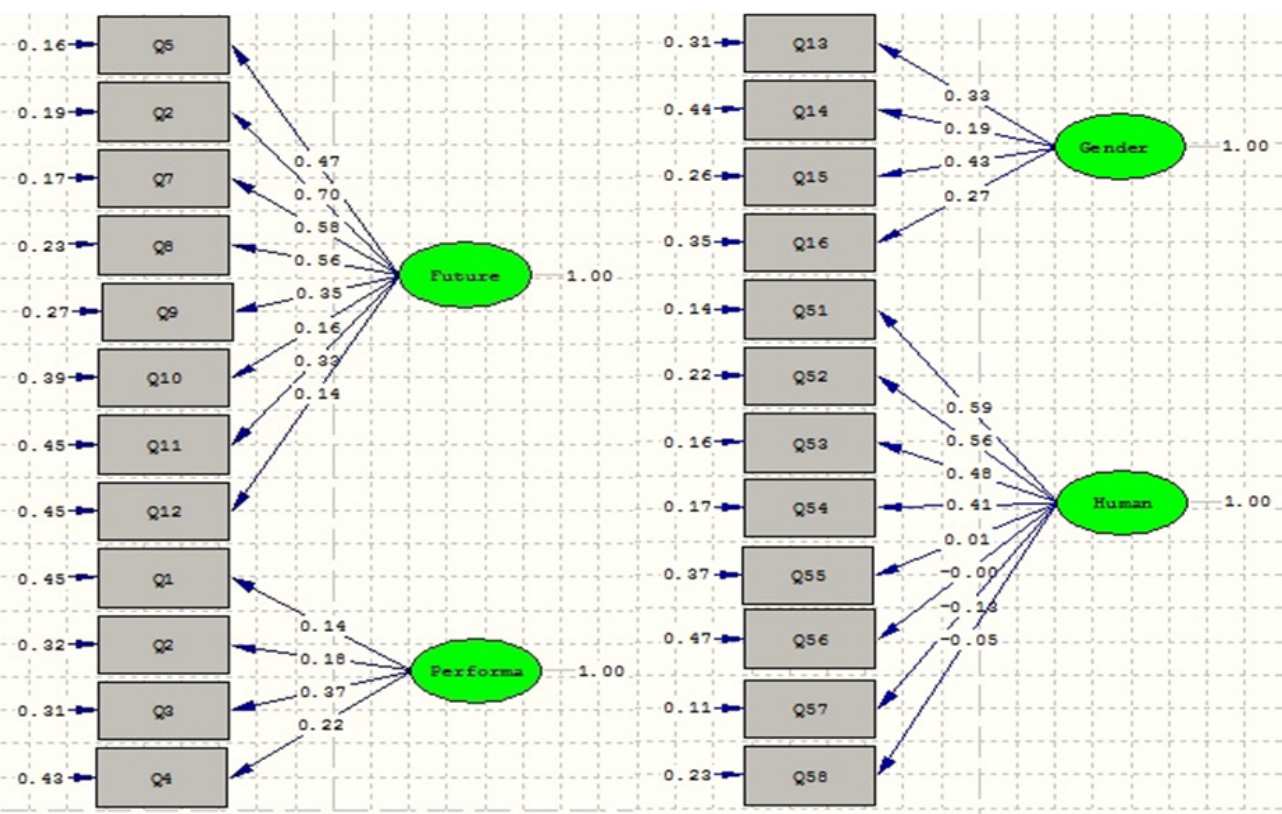

Figure 2. Factor loadings of the questions of cultural dimensions in the confirmatory factor analysis

Figure 2 shows the values of the factor loadings. Factor values more than 4.0 are acceptable.

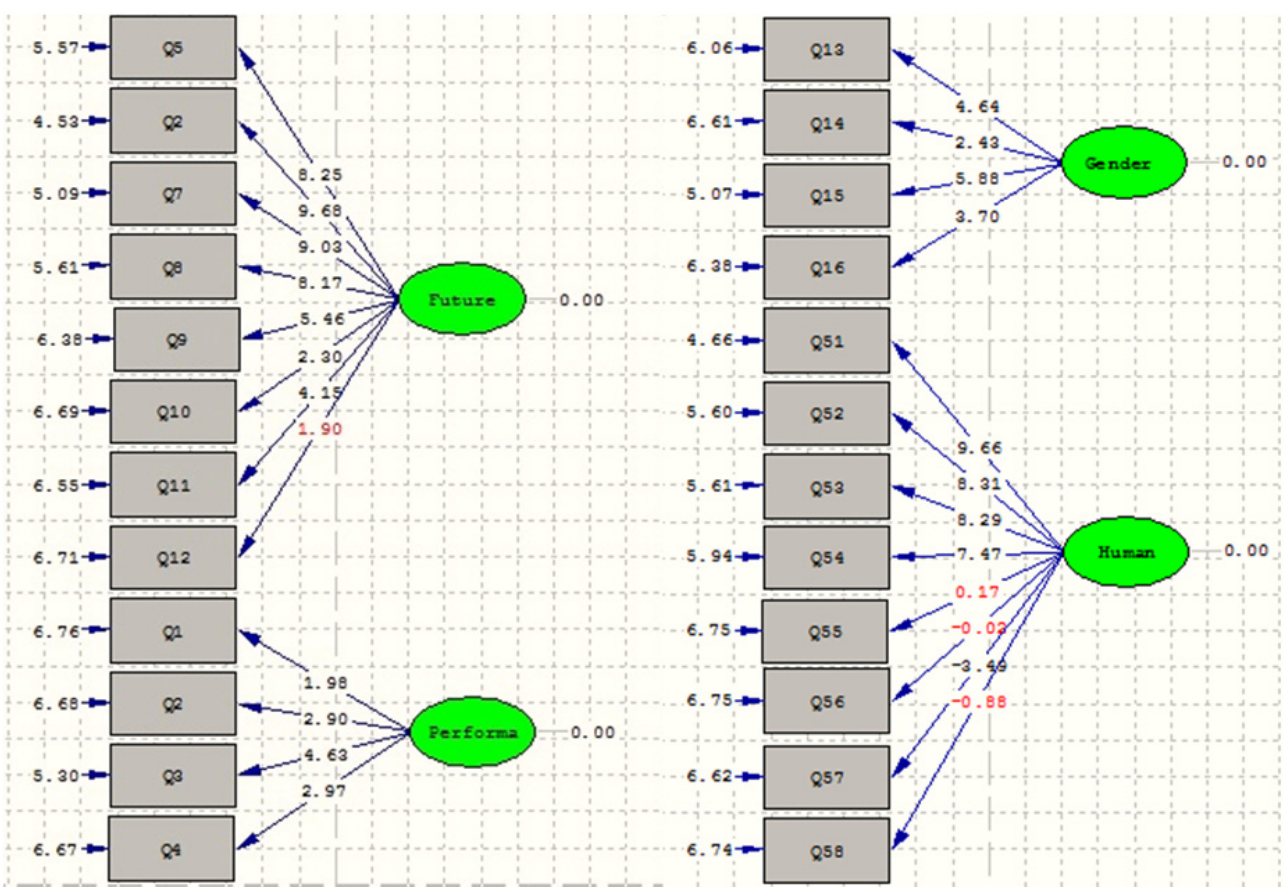

Figure 3 . T value of the questions of cultural dimensions in the confirmatory factor analysis

Figure 3 shows the $\mathrm{T}$ values. Based on these results it is evident that the first indicator of power distance dimension is not important to measure the structure of power distance, because the value of $\mathrm{T}$ is less than 1.96 and it should be removed from the model. Also, the third structure for avoidance dimension and fifth, sixth and tenth structures for collectivism and individualism dimension is not important. After removal of these structures, require analysis is performed. 


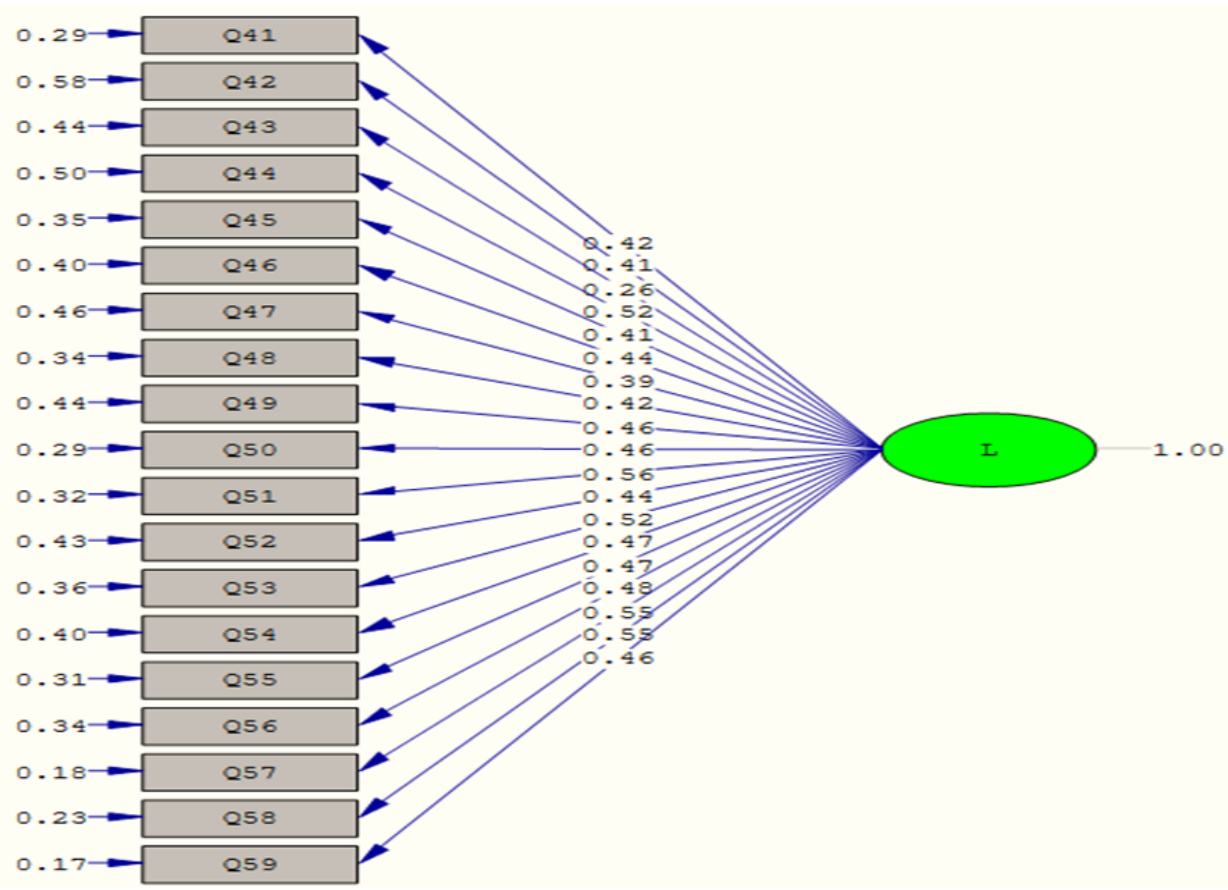

Figure 4. Factor loadings of the questions of understanding cultural differences in the confirmatory factor analysis

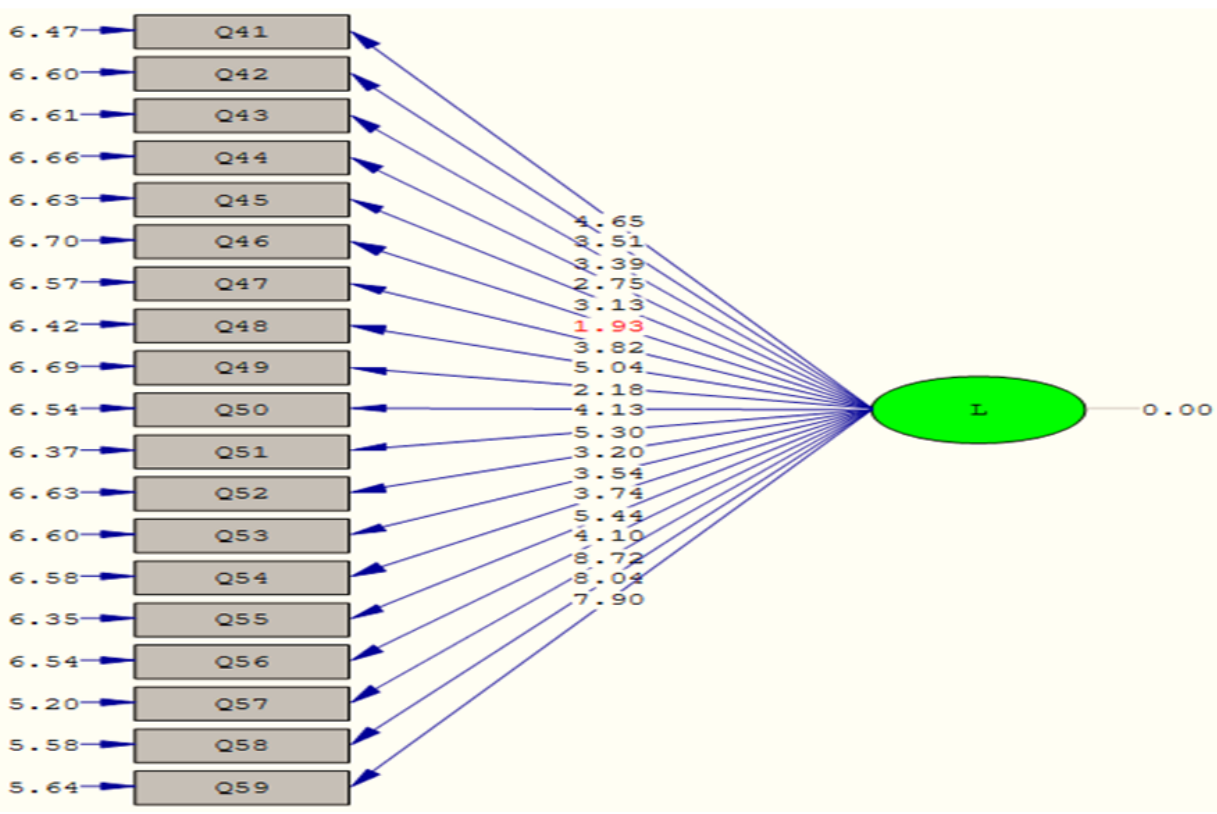

Figure 5. T value of the questions of understanding cultural dimensions in the confirmatory factor analysis

Figure 5 shows the $\mathrm{T}$ values. Based on these results it is evident that the seventh indicator of understanding cultural differences dimension is not important to measure the structure of understanding cultural differences, because the value of it is less than 1.96 and it should be removed from the model. After removal of these structures, require analysis is performed.

\subsection{Expression of Subjects}

Specifications of respondents were examined by four variables of age, gender, education and work experience. $90 \%$ of respondents were male and $10 \%$ were female. $30 \%$ of respondents aged between 24 and 27 years, $27 \%$ 
of those between 28 to 32 years, $13 \%$ of those aged between 33 to 37 years and $30 \%$ were older than 37 years. $50 \%$ of respondents were Bachelor of Science, $40 \%$ were Master of Science and $10 \%$ were $\mathrm{PhD}$. In terms of work experience of about $10 \%$ have served between 3 and 5 years, $40 \%$ have served between 6 and 9 years, $30 \%$ have served between 10 and 13 years, $15 \%$ have served between 14 and 17 years and $5 \%$ have served more than 17 years.

\subsection{Data Analysis and Hypothesis Tests}

Linear regression is used to modeling the value of a dependent variable based on its linear relationship to one or more predictor. The linear regression model assumes that there is a linear relationship (or straight line) between each dependent variable and predictor variable. This relationship is illustrated in the following formula (Houman, 2008).

$$
y_{i}=b_{0}+b_{j} x_{i j}+\ldots+b_{p} x_{i p}+e_{i}
$$

In which;

$y_{i}$ : Is the value of ith dependent variable.

$\mathrm{P}$ : Is the number of predictors.

$b_{j}$ : Is jth coefficient, $j=0, \ldots, p$

$\mathrm{X}_{\mathrm{ij}}$ : Is $\mathrm{jth}$ value of the ith predictor.

ei: Is the error in the ith observed value.

In this study, the economic indicators are the dependent variables and the cultural dimensions are the independent variables. Using multiple linear regressions cultural dimensions of economic indicators were evaluated.

\subsection{Research Findings}

The multiple linear regression is used in order to evaluate the impact of cultural dimensions on intercultural business communication. The results of the calculation are reported in Table 3:

Table 3. Table of regression coefficients of cultural dimensions impacts on intercultural business communication

\begin{tabular}{|c|c|c|c|c|}
\hline Dependent variable & Independent variable & Regression coefficient & T value & Significant level \\
\hline \multirow{5}{*}{ Intercultural business communication } & Boldness & 0.003 & 2.68 & 0.008 \\
\hline & Uncertainty avoidance & 0.011 & 8.23 & 0.000 \\
\hline & Power distance & -0.009 & -2.42 & 0.016 \\
\hline & Individualism and collectivism & 0.005 & 3.11 & 0.002 \\
\hline & Understanding cultural differences & 0.003 & 1.81 & 0.071 \\
\hline
\end{tabular}

Table 4. The results of the main hypotheses tests of the research

\begin{tabular}{llc}
\hline No. & \multicolumn{1}{c}{ Hypothesis } & \multicolumn{1}{c}{ Results } \\
\hline 1 & $\begin{array}{l}\text { Societies that have high boldness significantly are more successful in intercultural business } \\
\text { communication. }\end{array}$ & Approval \\
2 & $\begin{array}{l}\text { Societies that have high individualism significantly are more successful in intercultural } \\
\text { business communication. }\end{array}$ & Approval \\
3 & $\begin{array}{l}\text { Societies that have low power distance significantly are more successful in intercultural } \\
\text { business communication. }\end{array}$ & Approval \\
4 & $\begin{array}{l}\text { Societies that have low uncertainty avoidance significantly are more successful in intercultural } \\
\text { business communication. }\end{array}$ & Rejection \\
5 & $\begin{array}{l}\text { Societies that have high understanding of the cultural differences significantly are more } \\
\text { successful in intercultural business communication. }\end{array}$ & Rejection \\
\hline
\end{tabular}

According to the results in Table 4, whatever the boldness increases, power distance decreases and individualism increases in the societies, their success in intercultural business communication becomes higher.

\section{Conclusion}

The results show that, boldness has the most impact on gross domestic product, percentage of gross capital 
formation, percent of the value of exports and imports and has the least impact on the percentage of non-governmental consumption. So the countries who want to increase their gross domestic product, they should increase the boldness in the organizations' members. Because, boldness leads to the adoption of entrepreneurial orientation. Thus, societies with more courage in the organizations have better reactions in dealing with the ups and downs of business and trade. This issue is regarded as one of the cultural and moral driving forces like an engine for growth. Another point is that, economically the more rewards belong to organizations that increase the profits or reduce costs of production. This property theoretically has a strong and positive relationship with the decisiveness and boldness and has an inversed relationship with uncertainty avoidance. Therefore, it is recommended that, organizations which emphasize on being a leader in the markets (both internal and external), should hire managers with higher boldness and decisiveness and they should also strengthen these features in their cultural programs.

The results of the research show that, individualism has the most positive impact on the added value in mining and industry and then power distance has the most negative impact. Collectivism has the most positive impact on the added value in services, percent growth of the liquidity increase to GDB and the growth of consumer total index (inflation). Therefore, the results of research on the effects of collectivism and power distance were in line with the theoretical expectation of researchers. Basically the issue of individualism and collectivism is the most important factors that can be realized by means of the differences between the societies. One of the major consequences of collectivism for economic growth is preference of the interests of the organization or group to the individual interests. This causes that, innovation and risk taking be in a more suitable position than individualism. Individualism leads to solitary, preferring individual interests over group interests, risk aversion, an increase in the total error and the loss of industrial competitiveness. This in turn, leads to a decrease in exports and a decline in national production.

The negative impact of power distance can also be interpreted in the same direction. Basically, in groups and organizations that authoritarianism and centralization of power is higher, more individualism is seen and loyalty to the group is reduced and this is the negative effect that is accrued from individualism. It should be noted, though, individualism has a positive effect on entrepreneurship; but because of high power distance and a lack of profits raised from economies scale, these positive effects can be transient and unstable and doesn't ensure the sustainable growth of society.

Scholars such as Fukuyama (1999), Inglehart (1999), Biogls Dick et al. (2002) and Bengtson et al. (2005) believe that, one of the indicators of economic development is decreasing the cost of uncertainty and consequently increasing the trust. Because, in a society where trust is decreased, uncertainty avoidance will increase. People are extremely conservative, and innovation will decline (Rahmani \& Amiri, 2007).

Also, several studies in the field of management in the 21 st century represent evidence of strong positive relationship between competence of cultural understanding and commercial success in economic growth (Hofstede, 2001; Thomas \& Inkson, 2003; Tan, 2004; Peterson, 2004). Because, cultural differences have emerged as potential sources of conflict, in a way that, in the absence of clear understanding makes it difficult to develop a good business relationship (Trendys, 2006). Therefore, cultural diversity management in various business activities such as business communication (Gudykunst, 2003) and trade negotiations are used (Thomas \& Inkson, 2003; Peterson, 2004; Ferraro, 2006).

In the results of the study, two hypotheses concerning the relationship between uncertainty avoidance and understanding cultural differences in business communication success are not accepted. This contrasts with the results of the study that some of them were noted. Therefore, it can be concluded from the implicit findings of the research that Iran, according to data released by the World Bank ( Note 2), is economically in transition (or developing). In the developing countries, high uncertainty avoidance leads to lower levels of trust in the society. On the other hand, the scientific and practical abilities of the immigrated elite were unused in the business communications or the power of their influence is very limited. As a result, understanding of cultural differences will lose its effectiveness to develop the business communications (Rahmani \& Amir, 2007).

According to the above contents and importance of cultural dimensions; culture is a set of values, beliefs and opinions in a society that has the ability to influence and affect. The culture of a society doesn't form instantaneous and immediately. When it is formed, it doesn't disappear immediately. Thus, whatever the foundations of the cultural identity of a society be stronger, its effects on society will be less. On the other hand with the spread of globalization, increasing interdependence and interconnectedness of countries for economic development, people at all levels of the organization should be empowered through the cultural preparations.

At the organizational level, structural empowerment should be created. In this method the structures should be 
shattered, in the way in which the cultural dimension of power distance decreases and a structure is created, in which all people equally have the chance to be empowered.

At the management level, empowerment for participation in decision-making is delegation (strengthening the dimension of collectivism), which is called functionalist empowerment.

In humanist empowerment, with emphasis on human values and attention to the human and his dignity, it is tried to eliminate the root of the disability and intends to provide all empowerment aspects for them (strengthening the dimension of boldness) and increases the capacity of members to embrace innovation and change (management of the cultural dimension of uncertainty avoidance). Finally, strengthening the cultural dimensions leads to the understanding the cultural differences (Aarabi \& Fayazi, 2008).

For future research it can be suggested that:

- Evaluation the nine dimension GLOBE studies in non-governmental organizations and institutions and its impact on their success

- Evaluation and comparative study about the relationship of cultural dimensions and economic development in the GLOBE studied countries.

- Evaluation the effects of cultural dimensions of the GLOBE study on scientific development in the country

- Evaluation and comparative study of the impacts of cultural dimensions of the GLOBE study in governmental and non-governmental organizations

\section{References}

Ebrahimian, S. H. (2012). Rereading cultural engineering and cultural pathology in the higher education system. Soft Power Studies, 5, 150-121.

Abzari, M., \& Khani, A. (2010). Cultural intelligence, dealing with differences. Journal of Management Era, 16-17, 57-52.

Stoner, G. A. F., Freeman, R. A., \& Gilbert, D. R. (2005). Planning, Management in the 21st Century (AS. Parsaeian, \& S. A. M. Arabs, Trans.). Tehran: Office of Cultural Research.

Scott, R. (2003). Organizations: Rational, natural and open systems (H. Mirzai Ahranjany, Trans.). Tehran: The Side.

Aarabi, S. M., \& Omid, M. (2009). Human resources strategy, national culture and organization challenges. Human Resources, 2, 20-29.

Aarabi, S. M., \& Omid, M. (2008). The edition methodology and deployment the strategy of human resources empowerment in Iran's context of culture, Journal of Human Resource Management University of Imam Hussain (AS), 1(1), 18-1.

Aarabi, S. M., \& Hedayati, S. H. (2009). Strategy model based on the culture. Journal of Human Resource Management University of Imam Hussain (AS), 1(3), 145-127.

Eghdampour, A., Mehrdad, H., \& Jafari, H. (2011). Reviewing the relationship between personality traits and cultural intelligence of Lorestan province's Heritage, Handicrafts and Tourism personnel, Journal of Educational Psychology, 2(1), 181-101.

Beigi, A. H. (2011). Assessment of the factors affecting the cultural preservation of the Islamic Republic of Iran. Strategy Journal, 58, 366-335.

Pazokizadeh, Z., \& Tishehyar, M. (2010). Communication challenges in cultural relations. Fantastic, 219, 21-13.

Pour Ezzat, A. A., Gholipour, A., Bagheri, M., \& Naddaf, M. (2011). The effects of globalization on the trade policy of the Islamic Republic of Iran. Journal of Business Management, 3(10), 54-35.

Tajik, M. R., \& Darvishi, F. (2004). Ideals of the Islamic Revolution in the Age of Globalization: Challenges and Responses. Of Sociology, 5(3), 140-171.

Tavakol Nia, M. R., \& Zahedmehr, A. (2011). Analysis of the impact of globalization on the index of quality of life, QOL, based on data panel estimates for oil exporting countries. International Journal of Strategic Studies, 3, 19-26.

Johich, M. (2002). Organization theory: modern, symbolic, interpretive, postmodern (H. Danaei Fard, Trans.). Tehran: Publishing Opinion.

Hamidi, M., Andam, R., \& Feizi, S. (2013). Cultural intelligence aspects of volunteers in sport. Sport Management, 5(3), 20-5. 
Khanifar, H., Zarvandi, J., \& Zarvandi, N. (2010). Globalization and messianic Culture views of the Qur'an and Islamic tradition. Promised east, 4(16), 91-115.

Dadmehr, L. S. (2010). The impact of technology on organizational communication. Bank, 51-50, 112-106.

Robinz, A. P. (1996). Organizational Behavior (AS. Parsaeian, SA. M. Arabs, Trans.). Tehran: Office of Cultural Research, 3.

Robinz, A. P. (1998). Organizational Behavior (AS. Parsaeian, SA. M. Arabs, Trans.). Tehran: Office of Cultural Research, 1 .

Rahmani, T., \& Amiri, M. (2007). The effect of trust on economic growth in provinces with spatial econometric approach, Journal of Economic Studies, 78, 57-23.

Ranjkesh, J. (2010). Globalization. Paper presented at the Second Conference on Islamic Economics and development, Ferdowsi University of Mashhad, Mashhad.

Zahedi, Sh. A. (2011). Globalization and sustainable development. International Journal of Strategic Studies, 3 , $1-18$.

Safiri, Kh., \& Nematollahi, Z. (2012). The relationship between instruments of globalization and religious identity. Social Studies and Research, 1(1), 39-70.

Sadeghi, A., Jafari, H., Khodayari, R., Pakdaman, M., Mohammadi, R., \& Ahadi Nezhad, B. (2011). The relationship between organizational culture and knowledge management. Hospital Quarterly, 10(2), 8-1.

Ameli, S. R. (2007). The major challenge of cultural engineering. Cultural Engineering Magazine, 10-11, 18-25.

Oughi, V. (2011). Collectivism and individualism of our culture messianic vision. Islam and Management Research, 1 (2), 9875.

Ghaheri, R. (2010). Globalization and Education. Culture and Globalization Research, 1, 71-98.

Mostafavi, S. M. (1392). The effect of globalization on market opportunities for goods and solvent services (Brand). Journal of Islamic Banking and Economics, 2, 137-167.

Mcveli, J., Duberley, Zh., \& Johnson, F. (2007). Organization theory: perspective and challenges (H. Danaei Fard, \& S. H. Kazemi, Trans.). Tehran: University of Imam Sadiq (AS), Volume I and II.

Mansouri Sepehr, R., Motiei, H., Shekarriz, J., \& Nejati, V. (2013). Assessment factor structure and reliability of the questionnaire of cultural values. Journal of Occupational and Organizational Consultation, 5(15), 71-57.

Mehrban Far, A., \& Noubari, S. (2013). The role of culture on entrepreneurial alertness in Iran using data from GEM, Journal of Technology Management, 9(34).

Fani, A., Babashahi, J., Afkhami Ardakani, M., \& Ebrahimi, M. (2012). Promoting entrepreneurship, analyze the role of the cultural model parameters Globe. Entrepreneurial Development, 5(2), 144-125.

Faghihi, A., Vaezi, R., \& Aghaz, A. (2010). Focusing on the interaction between the bureaucracy and the culture in Iran. Journal of Management Sciences, 19, 31-1.

Houman, H. A. (2008). Structural equation modeling using Lisrel, Tehran: The Side.

Ameli, S. R. (2004). Global Space: Powerfulness \& Powerlessness of Cultures, University of Tehran, Journal of Social Science, 22(11), 99-81.

Chhokar, J. S., Brodbeck, F. C., \& House, J. R. (2007). Culture and Leadership Across the World: The GLOBE Book of In-Depth Studies of 25 Societies. New Jersey: Lawrence Erlbaum Associates, Publisher.

Eisenberg, E. M., Goodall, H. L. \& Trethewey, A. J. R. (2010). Organizational Communication, (6th ed.). New York: Boston.

Gudykunst, W. B. (2003). Cross-Cultural and Intercultural Communication, Thousand Oaks. CA: SAGE, Yarmouth, ME: Intercultural Press.

Hofstede, G. (2001). Culture Consequences: Comparing value, Behaviors, Institutions and Organization Cross Nation, Thousands Oaks.

House, J. R., Hanges, P. J., Javidan, M., Dotfman, P. W., \& Gupta, V. (2004). Culture, leadership and organizations (The GLOBE study of 62 Societies). London: SAGE Publications.

Hwang, B. Y. (2005). Globalization, Strategic Culture, and Ideas: Explaining Continuity in Kore and Foreign 
Economic Policy, Unpublished Ph. D, Georgetown University. United State, Washington.

Imai, R. (2007). The Culturally Intelligent Negotiator: The Impact of CQ on Intercultural Negotiation Effectiveness, Thesis, University of Maryland.

Jaros, S. (2010). Commitment to organizational change: A critical review, Journal of Change Management, 10(1), 79-108.

Lee, J. N., \& Kim, Y. G. (1999). Effect of Partnership Quality on IS Outsourcing Success: Conceptual Framework and Empirical Validation. Journal of Management information systems, 15(4), 29-61.

Liu, Y. (2012). Exploring the Impacts of Cultural Globalization on Cultural Awareness/Values and English, Writing in Chinese Context, Intercultural Communication Studies, 2(2), 110-94.

Mikami, K. (2011). Cultural Globalization in People's Life Experiences: Japanese Popular Cultural Styles in Sweden, Unpublished Ph. D, Stockholm University. Sweden, Stockholm.

Millar Wood, J. C. (2008). The Impact of Globalization on Educcation Reform: A Case Study of Uganda, Unpublished Ph. D, Maryland University. United State, Maryland.

Miller, K. (2011). Organizational Communication: Approaches and Processes (6th Ed.). New York: Lyn Uhl.

Movius, L. (2010). Cultural Globalisation and Challenges to Traditional Communication Theories, University of Southern California, USA, Journal of Media and Communication, 2(1), 18-6.

Nunnally, J. C. (1978). Psychometric Theory (2nd ed.). New York: McGraw-Hill.

Peterson, B. (2004). Cultural Intelligence: A Guide to Working with People from Other Cultures. London: Nicholas Brealey.

Tan, J. (2004). Cultural Intelligence and the Global Economy. Leadership in Action, 24(5), 19-21.

Prado, \& William, H. (2006). The Relationship between Cultural Intelligence and Perceived Environmental Uncertainty, Ph. D, University of Phoenix.

Thomas, D. C., \& Inkson, K. (2003). Cultural Intelligence: People Skills for Global Business, San Francisco: Berrett-Koehler Publishers.

Tomlinson, J. (1999). Globalization and Culture, University of Chicago Press.

Tourish, D., \& Hargie, O. (2004). Key Issues in Organizational Communication, (6rd Ed.). New York: Routledge.

Triandis, \& Harry, C. (2006). Cultural Intelligence in Organizations, Group \& Organization Management, 32(1), 20-26.

Turner, B. (2004). The sociology of cultural resistance to globalization: strong aesthetic/ weak structure. Journal of Social Science, 11(2), 17-32.

Wang, Y. (2007). Globalization Enhances Cultural Identity. Intercultural Communication Studies, 6(1), 83-86.

\section{Notes}

Note 1. It is worth mentioning that in America, as well as scholars and experts in this field, commonly use the term CQ stands for Cultural Quotient for this phrase.

Note 2. www.worldbank.org

\section{Copyrights}

Copyright for this article is retained by the author(s), with first publication rights granted to the journal.

This is an open-access article distributed under the terms and conditions of the Creative Commons Attribution license (http://creativecommons.org/licenses/by/4.0/). 